\title{
Solid state fermentation of pomegranate seed for lovastatin production: A bioprocessing approach
}

\author{
Azza S. Naik, Smita S. Lele* \\ Food Engineering and Technology Department, Institute of Chemical Technology, Mumbai, India \\ Email: *dr.smita.lele@gmail.com
}

Received 20 June 2012; revised 28 July 2012; accepted 16 August 2012

\begin{abstract}
This study reports lovastatin production by solid state fermentation using pomegranate seeds as a substrate. Six different fungal strains and several agro-industrial wastes were selected and screened. Various physicochemical parameters were optimized to improve lovastatin productivity. Moreover, chemical mutation was system-atically employed to enhance lovastatin yield on selected strains. Productivity of $\mathbf{3} \pm \mathbf{0 . 0 6} \mathbf{~ m g}$ lovastatin/gm dfm was obtained prior to optimization. One factor a time followed by Response Surface Methodology (RSM) gave $4.2 \pm 0.10 \mathrm{mg}$ lovastatin $/ \mathrm{gm} \mathrm{dfm}$ yield in an optimized setup with pomegranate seed powder (5 gms), $\mathrm{KH}_{2} \mathrm{PO}_{4}(0.1 \% \mathrm{w} / \mathrm{v})$, glucose $(5 \%$ $\mathrm{w} / \mathrm{v})$, moisture $(60 \% \mathrm{w} / \mathrm{w})$, $\mathrm{pH} 5$ in a 15 days fermentation cycle. The production was further increased to $6.5 \pm 0.08 \mathrm{mg}$ lovastatin $/ \mathrm{gm} \mathrm{dfm}$ through chemical mutation of the strain. This process is simple and reproducible for the production of lovastatin using pomegranate seed as an agro-industrial waste.
\end{abstract}

Keywords: Lovastatin, Pomegranate Seeds; Solid Substrate Fermentation; Aspergillus terreus

\section{INTRODUCTION}

Pomegranate (Punica granatum) is a tropical fruit commonly grown in Indian subcontinent. Recently, the fruit gained public interest due to its remarkable antioxidant properties [1]. A number of pomegranate processing industries have been set up in India for last few years. This has led to a boost in the number of processed products like jams, jellies, juices, carbonated beverages, syrups, liqueurs and as osmotically dehydrated bits in fruit bars [2]. The edible part of pomegranate represents $52 \%$ of total fruit weight, comprising of $78 \%$ juice and $22 \%$ seeds [3]. Processing of this fruit is such that the peels and seeds get automatically separated resulting in tons of easily utilisable segregated fruit waste. In spite of high pro-

${ }^{*}$ Corresponding author. duction of fruits in general and pomegranate in particular, India like other developing countries lacks adequate post harvest facilities. Inadvertently, an agro-industrial project faces economic inviability. Fruit waste utilisation by fermentation for value added products instead of conventional applications such as cattle fodder or compost generation can positively change the current scenario.

Lovastatin, a fungal secondary metabolite acts as a competitive inhibitor of HMG-CoA reductase enzyme that catalyzes the rate limiting step of cholesterol biosynthesis [4]. This is due to the structural similarity of its acid form with HMG-CoA (the natural substrate of reductase), thus finding an application as a potent hypercholesterolemia drug [5]. Although many fungal genera like Penicillium, Monascus, Trichoderma, Pleurotus, Doratomyces have been reported to produce lovastatin; Aspergillus is the most commonly used one for its robust nature [6]. Several papers have also reported the effect of major nutrients like carbon and nitrogen on productivity of this biomolecule from the aforementioned fungus. However, most of these studies have been performed under submerged conditions utilising complex media [7-9]. Solid Substrate fermentation on the contrary involves solid support with little or no water. It is termed as the "low-technology" system; ideal for production of high cost-low bulk pharmaceuticals [10]. Here we report solid substrate fermentation of pomegranate seeds using Aspergillus terreus IFO 7078 strain, as an alternative process strategy to increase the productivity, simplify the downstream processing and utilize the waste as well.

\section{MATERIALS AND METHODS}

\subsection{Chemicals}

All media components were purchased from Himedia, Mumbai, India unless and otherwise mentioned. High performance liquid chromatography (HPLC) grade acetonitrile was obtained from SD-Fine chemicals along with other chemicals like Ammonium carbonate, Ammonium sulphate, Ammonium chloride, Ammonium nitrate, Magnesium sulphate $\left(\mathrm{MgSO}_{4}\right)$, Sodium nitrate $\left(\mathrm{NaNO}_{3}\right)$, 
and Potassium dihydrogen phosphate $\left(\mathrm{KH}_{2} \mathrm{PO}_{4}\right)$. Standard sample of lovastatin was gifted by Biocon Ltd. Pomegranate seeds \& Mango peel powder were obtained from Jain Irrigation Ltd., India while other substrates were obtained from a local market.

\subsection{Screening Studies}

The Six fungal strains (IFO7078, IFO 4520, Isolate 3A, NRRL 680, NRRL 1841 \& NRRL 1596) were screened for lovastatin production under submerged condition using media previously reported in literature (Table 1). IFO7078 strain of $A$. terreus was selected for further studies. Once organism was selected, screening of various substrates like Mango peel powder, Ashgourd peel powder, Pomegranate peel powder and Passion fruit peel powder was done. Thereafter, the best results were compared with the substrate of interest i.e. Pomegranate seed powder. In addition, proximate analysis of the substrate was done. Comparative study on the effect of defatted and non-defatted substrate was also carried out.

\subsection{Culture Maintenance and Inoculum Development}

IFO7078 strain of A. terreus was maintained on Potato dextrose agar slants. It was periodically subcultured every 15 days. Inoculum preparation was done by suspending spores in a sterile solution of $0.1 \%(\mathrm{v} / \mathrm{v})$ tween 80 . This solution was centrifuged and spores were re-suspended in saline. O.D of the spores was adjusted to $3 \times 10^{8}$ spores per ml. This spore suspension was then used to inoculate pre-autoclaved medium.

Table 1. Screening of strains for lovastatin production under submerged conditions.

\begin{tabular}{|c|c|c|c|}
\hline Strain & Organism & Media & $\begin{array}{l}\text { Lovastatin } \\
\text { yield mg/L }\end{array}$ \\
\hline IFO 7078 & A. terreus & $\begin{array}{l}\text { SF1 Gyorgy Szakacs } \\
\text { et al. (1998) }\end{array}$ & 200 \\
\hline IFO 4520 & M. pilosus & $\begin{array}{c}\text { GGP Tsuyoshi } \\
\text { Miyake et al. (2006) }\end{array}$ & 150 \\
\hline Isolate 3A & A. terreus & $\begin{array}{c}\text { SF1 Gyorgy } \\
\text { Szakacs et al. (1998) }\end{array}$ & - \\
\hline NRRL 680 & A. terrues & $\begin{array}{c}\text { SF1 Gyorgy } \\
\text { Szakacs et al. (1998) }\end{array}$ & - \\
\hline NRRL 1841 & P. citrinum & $\begin{array}{l}\text { Malt, glucose } \\
\text { and peptone. }\end{array}$ & - \\
\hline NRRL 1596 & M. purpureus & $\begin{array}{l}\text { Dextrose containing media } \\
\text { Sadik Sayyad et al. (2007) }\end{array}$ & 90 \\
\hline
\end{tabular}

Based on the reported literature appropriate media was used for respective strain. Uniform condition maintained during screening of different strains. Temperature was $28^{\circ} \mathrm{C}$ and the experiment was carried out under shake flask condition.

\subsection{Substrate Preparation}

Pomegranate seeds were oven dried at $50^{\circ} \mathrm{C}$ for $24 \mathrm{~h}$ or till a constant weight was achieved. Seeds were then ground to a uniform particle size and passed through a sieve to separate coarse particles.

\subsection{Substrate Defatting}

Defatting of pomegranate seeds was achieved by Soxlet apparatus using petroleum ether as the preferred solvent for fat extraction.

\subsection{Fermentation Optimisation}

5 gms of dried pomegranate seed powder having particle size in the range of 250 - 800 microns was autoclaved at $121^{\circ} \mathrm{C}$ for $20 \mathrm{~min}$ in a $250 \mathrm{ml}$ flask. Separately autoclaved solutions of carbon, nitrogen and salt supplements were used to wet the substrate, adjusting the moisture content at appropriate levels. Several physic-chemical parameters were optimised using one factor at a time method (Figure 1).

Moisture was adjusted to levels 50\%, 60\%, 70\%, 80\% and $90 \%(\mathrm{w} / \mathrm{w})$. Optimisation studies for temperature as a parameter were carried out at $22^{\circ} \mathrm{C}, 25^{\circ} \mathrm{C}, 28^{\circ} \mathrm{C}$, and $30^{\circ} \mathrm{C}$. Production profile was made on the basis of lovastatin content every 3 days for 18 days. Carbon sources such as Glucose, Fructose, Sucrose, Lactose, Maltose, Galactose, and Glycerol were screened. Various nitrogen sources were screened (at $1 \% \mathrm{w} / \mathrm{v}$ ) as supplements like (organic sources) Tryptone, Urea, Malt extract, Beef extract, Yeast extract, Soyabean meal, Peptone and (inorganic sources); Ammonium carbonate, Ammonium Sulphate, Ammonium chloride, Ammonium nitrate. Minerals like $\mathrm{Mg}$, $\mathrm{Na}$ and $\mathrm{K}$ were used as $\mathrm{MgSO}_{4}, \mathrm{NaNO}_{3}$, and $\mathrm{KH}_{2} \mathrm{PO}_{4}$, for optimisation studies.

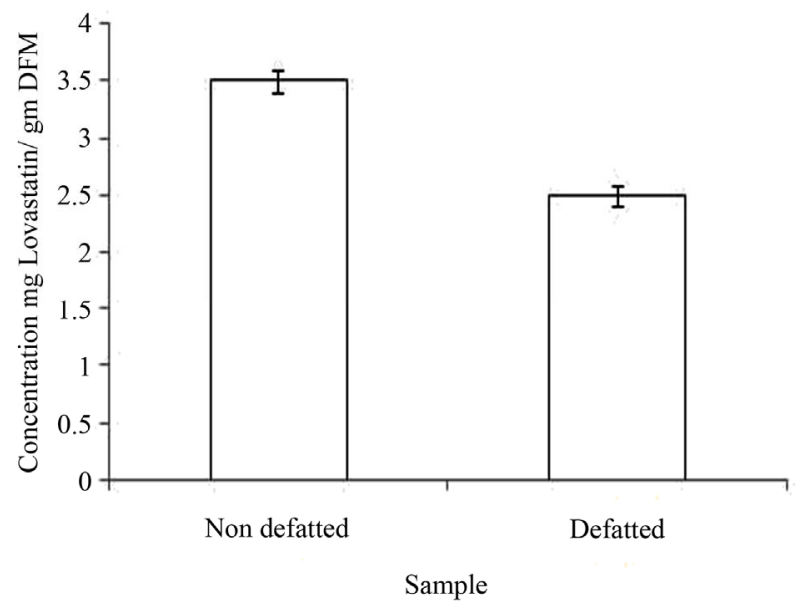

Figure 1. Comparison of lovastatin productivity on defatted versus non defatted substrate. 


\subsection{Extraction}

A mixture containing Acetonitrile:Water $(1: 1 \mathrm{v} / \mathrm{v})$ was added to the flask containing fermented matter and was sonicated for $5 \mathrm{~min}$. The flask was then placed on Rotary shaker for 12 hrs. The broth was centrifuged at 10,000 rpm for $10 \mathrm{~min}$ followed by filtering it through $0.22 \mathrm{mi}-$ cron filter. The extracted sample was then subjected to HPLC analysis.

\subsection{Analytical Method}

Lovastatin was quantitatively analysed using HPLC (JASCO, India) with Hemilton $\mathrm{C}_{18}$ column $(250 \times 4.6$ mm I.D) and solvent system of HPLC Grade acetonitrile containing $0.1 \%$ orthophosphoric acid $(60: 40 \mathrm{v} / \mathrm{v})$ as the mobile phase $(1 \mathrm{ml} / \mathrm{min})$. Peaks were detected at $238 \mathrm{~nm}$ using U.V detector (Figure 2).

\subsection{Response Surface Methodology}

Response surface methodology (RSM) by central composite design using DESIGN EXPERT 7.0 was implemented to batch cultures of $A$. terreus, for identifying the effects of three independent process parameters i.e $\mathrm{KH}_{2} \mathrm{PO}_{4}$, glucose and $\mathrm{pH}$ of medium on production of lovastatin. Each factor was varied at three levels. The experimental design consisted of 20 runs with six replicates of the central point to determine the experimental error. Regression analysis was performed on the data obtained from the design experiments.

\subsection{Strain Improvement Studies}

Ethyl methyl sulphonate (EMS), an alkylating agent was used at concentrations of $0.15 \mathrm{M}, 0.3 \mathrm{M}$ and $0.5 \mathrm{M}$ respectively and each concentration was incubated with spores for time periods of 30, 60, 90 and 120 minutes. The procedure involved treating loopful of spores with the above concentrations of EMS for respective time

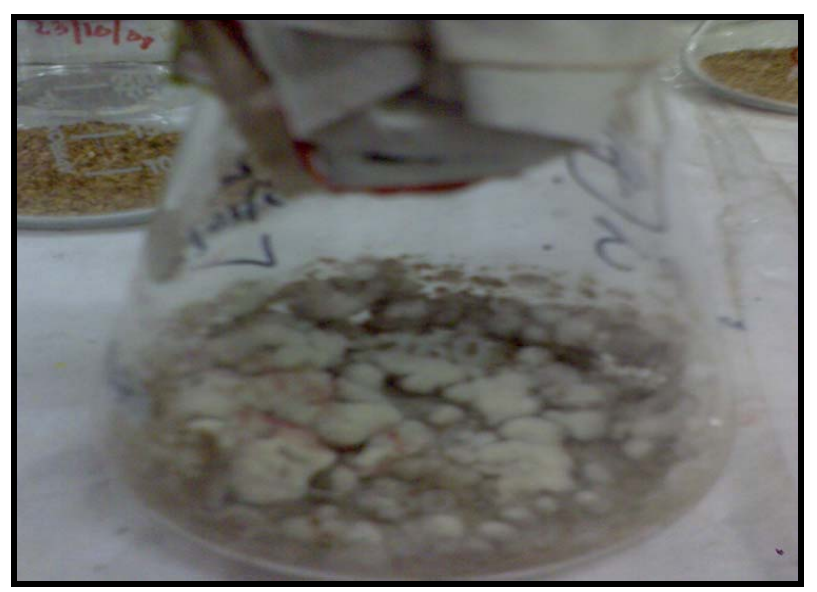

Figure 2. Flask level SSF batch on pomegranate seed powder. duration and subsequently curbing the reaction by addition of stopping agent sodium thiosulphate. The spores were then serially diluted and inoculated onto PDA plates. Random colonies were picked, about 10 colonies per plate and subcultured. The resultant colonies were checked for lovastatin production.

\section{RESULTS AND DISCUSSION}

In this study we report utilization of pomegranate seeds for the production of lovastatin by solid state fermentation. Preliminary experiment was conducted on standard reported media under submerged condition to select suitable fungal strain. Of the six strains screened; $A$. terreus IFO7078 was found to give maximum yield of lovastatin (Table 1). Hence this strain was selected for further studies.

\subsection{Defatted versus Non-Defatted Substrate}

The use of defatted substrate has been reported to give better productivity of statins by filamentous fungi [5]. Proximate analysis showed that pomegranate seed is rich in fat content (Table 2). Hence we carried out a comparative study on defatted and non-defatted substrate. Defatted substrate was less suitable compared to nondefatted for lovastatin productivity which is in agreement with previous report on soya bean substrate [4]. Comparative profile of lovastatin production on defatted and non defatted pomegranate seed substrate is shown in Figure 1. Absence of lovastatin production on pomegranate peels, mango peels and passion fruit peels might be due to lesser amount of fats (Table 2) and considerable amount of phenolics (data not shown) which prevents the growth of micro-organisms [11]. Thus it can be concluded that Pomegranate seeds are favourable choice for lovastatin production.

Table 2. Fat content of substrate and corresponding lovastatin yield on it.

\begin{tabular}{ccc}
\hline Substrate & Fat content & $\begin{array}{c}\text { Lovastatin yield } \\
\text { mg/gm DFM }\end{array}$ \\
\hline $\begin{array}{c}\text { Mango peel } \\
\text { powder }\end{array}$ & $2.22 \pm 0.06$ & - \\
$\begin{array}{c}\text { Pomegranate } \\
\text { peel powder }\end{array}$ & $0.13 \pm 0.02$ & - \\
$\begin{array}{c}\text { Passion fruit } \\
\text { peel powder }\end{array}$ & $1.08 \pm 0.04$ & - \\
$\begin{array}{c}\text { Ashgourd } \\
\text { peel powder }\end{array}$ & $5.0 \pm 0.10$ & $2.8 \pm 0.04$ \\
$\begin{array}{c}\text { Pomegranate } \\
\text { seed powder }\end{array}$ & $32 \pm 0.11$ & $3.0 \pm 0.06$ \\
\hline
\end{tabular}




\subsection{Optimisation of Lovastatin Yield}

Different physical and chemical parameters were considered in our study. Primary batches of SSF proved that thorough mixing of substrate after inoculation and moisture addition was crucial for enhanced mycelial development (Figure 2) and eventual lovastatin production. Maximum productivity (3.42 $\mathrm{mg} / \mathrm{gm} \mathrm{dfm}$ ) was obtained at $60 \%$ moisture level. Incubation temperature $\left(25^{\circ} \mathrm{C}\right)$ and $\mathrm{pH} 5$ was found to be optimum for lovastatin production (3.60 $\mathrm{mg} / \mathrm{gm} \mathrm{dfm}$ ). From the growth curve the maximum yield of $3.68 \mathrm{mg} / \mathrm{gm} \mathrm{dfm}$ was obtained on $15^{\text {th }}$ day (Figure 3). Hence, physical factors did not affect lovastatin production to great extent, indicating the robustness of SSF as compared to submerged fermentation which is known to be highly sensitive to such parameters. The various chemical parameters considered in our study were carbon, nitrogen and mineral sources. Contrary to popular belief about glucose repression, the present study found it to be the best carbon source (at $5 \% \mathrm{w} / \mathrm{v}$ ) to give highest productivity of lovastatin (3.72 $\mathrm{mg} / \mathrm{gm} \mathrm{dfm})$. This could be attributed to the fact that pomegranate seeds have a high content of slow metabolising sugars and in combination with glucose supplement (fast metabolising) would result in better productivity [12]. Nitrogen repression of lovastatin productivity is an established phenomenon [8] and was further backed by our results wherein highest productivity was seen in control batches having no added nitrogen content. Thus supplementation with nitrogen sources was seen to repress lovastatin production in our study. Minerals were seen to play a crucial role in enhancing productivity and this could be due to the trace element requirement of specific strain. Of the minerals screened $\mathrm{KH}_{2} \mathrm{PO}_{4}$ gave a definite increase in the yield (3.90 mg/gm dfm).

Though RSM was performed not much increase in productivity was seen after one factor at a time optimisation. Maximum production of lovastatin obtained using optimized medium was $4.2 \pm 0.03$ (mg/g of $\mathrm{dfm}$ ) post RSM.

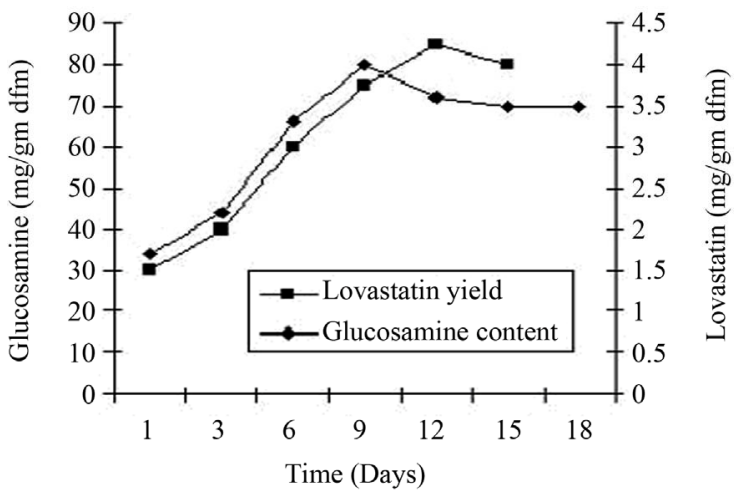

Figure 3. Production profile along with biomass concentration.

\subsection{Mutation Studies}

Beyond a certain point lovastatin yield failed to increase and this was observed after RSM application to our system. Thus further increase would need changes at the genetic level. Hence mutation studies were carried out to further increase lovastatin yields (Table 3). Of the several colonies picked after exposure to EMS (Ethyl Methyl Sulphonate), about 6 colonies showed lovastatin yield (highest $6.5 \pm 0.07 \mathrm{mg} / \mathrm{gm} \mathrm{dfm}$ ) higher than the control/untreated colonies (Figure 4). These colonies were subcultured for three generations on PDA and checked for lovastatin yield under both solid state fermentation and submerged conditions. High lovastatin productivity obtained consistently for three generations indicated positive effect of mutagen treatment. Enhanced productivity could be a result of alteration in the related metabolic pathway with the probable result of yet again relieving feedback inhibition commonly seen in lovastatin producing cultures [13]. Yield of lovastatin by different wild and mutant strains on varied solid substrates in our study is shown in Table 4.

\section{CONCLUSION}

Various fruit-vegetable peels and seeds were tried as substrates for lovastatin production by fungal cultures.

Table 3. Methodology for Mutant clones with increased yield.

\begin{tabular}{ccc}
\hline Nomenclature & EMS concentration & Exposure time \\
\hline M2-30a & $0.3 \mathrm{M}$ & $30 \mathrm{~min}$ \\
M1-30b & $0.15 \mathrm{M}$ & $30 \mathrm{~min}$ \\
M2-60a & $0.3 \mathrm{M}$ & $60 \mathrm{~min}$ \\
M1-60b & $0.15 \mathrm{M}$ & $60 \mathrm{~min}$ \\
M1-60a & $0.15 \mathrm{M}$ & $60 \mathrm{~min}$ \\
M3-60b & $0.5 \mathrm{M}$ & $60 \mathrm{~min}$ \\
\hline
\end{tabular}

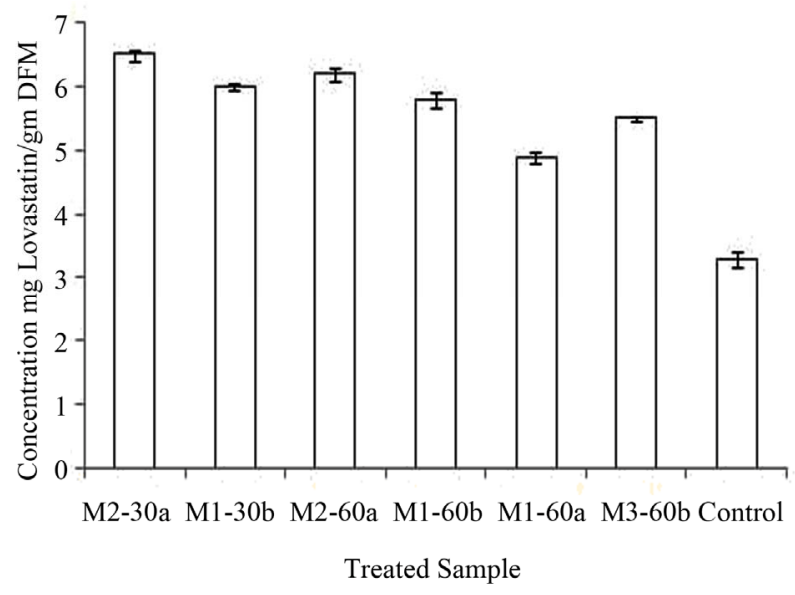

Figure 4. Effect of EMS exposure on lovastatin productivity. 
Table 4. Lovastatin yield of IFO 7078 compared with other strains.

\begin{tabular}{llll}
\hline Strain & Productivity mg/gm dfm & Substrate & Reference \\
\hline A. terreus & $6.50 \pm 0.08$ (mutant) & Pomegranate seed & Present work \\
IFO 7078 & $4.20 \pm 0.10$ (wild) & Wheat bran & Pansuriya and Singhal, 2010 [14] \\
$\begin{array}{l}\text { A. terreus UV 1718 } \\
\text { A. terreus ATCC 20542 }\end{array}$ & 3.72 (mutant) & $\begin{array}{l}\text { Rice or wheat bran } \\
\text { Extracted sweet sorghum pulp }\end{array}$ & Wei, 2007 \\
A. terreus TUB F-514 & 1.90 & supplemented with cheese whey & Szakács et al., 1998 \\
Monascus purpureus MTCC 369 & 3.42 & Rice based solid medium & Sayyad, S. A., et al., 2009 [15] \\
M. pilosus M12-69 & 2.52 & Red fermented rice & Chen and Hu, 2005 [16] \\
\hline
\end{tabular}

Pomegranate seeds were found to be the best substrate and with $0.1 \% \mathrm{w} / \mathrm{v}$ Potassium dihydrogen phosphate $\left(\mathrm{KH}_{2} \mathrm{PO}_{4}\right), 5 \% \mathrm{w} / \mathrm{v}$ glucose, $60 \% \mathrm{w} / \mathrm{w}$ moisture, $\mathrm{pH} 5$ with 15 days fermentation cycle under optimized solid state fermentation conditions, $4.2 \pm 0.03 \mathrm{mg}$ lovastatin/gm dfm was produced. Suitability of substrate was found to depend on presence of fats in the substrate. Further increase in productivity was obtained by mutation studies using Ethyl Methyl Suplphonate (EMS) to give a maximum lovastatin yield of $6.5 \pm 0.07 \mathrm{mg} / \mathrm{gm}$ $\mathrm{dfm}$. Thus a SSF process for pomegranate seeds utilization was developed with the aim to make pomegranate processing industry a truly profitable venture.

\section{ACKNOWLEDGEMENTS}

The authors of this study would like to express their gratitude to DBT, India for sponsoring the above study through allotment of contingency and fellowship.

\section{REFERENCES}

[1] Jurenka, J. (2008) Therapeutic applications of pomegra nate (Punica granatum L.): A review. Alternative Medicine Review, 13, 128-144.

[2] Aghsaghali, A.M. (2011) Evaluating potential nutritive value of pomegranate processing by-products for ruminants using in vitro gas production technique. ARPN Journal of Agricultural and Biological Science, 6, 45-51.

[3] EL-Nemr, S.E., Ismail, I.A. and Raga, M. (1990) Chemical composition of juice and seeds of pomegranate fruit. Die Nahrung, 34, 601-606. doi:10.1002/food.19900340706

[4] Xu, B., Wang, Q., Jia, X. and Sung, C. (2005) Enhanced lovastatin production by solid substrate fermentation of Monascus rubber. Biotechnology and Bioprocess Engineering, 10, 78-84.

[5] Manzoni, M., Bergomi, S., Rollini, M. and Cavazzoni, V. (1999) Production of statins by filamentous fungi. Biotechnology Letters, 21, 253-257. doi:10.1023/A:1005495714248

[6] Samiee, S.M., Moazami, N., Haghighi, S., Mohseni, F.A., Mirdamadi, S. and Bakhtiari, M.R. (2003) Screening of lovastatin production by filamentous fungi. Iranian Biomedical Journal, 7, 29-33.
[7] Szakács, G., Morovján, G. and Tengerdy, R.P. (1998) Production of lovastatin by a wild strain of Aspergillus terreus. Biotechnology Letters, 20, 411-415. doi:10.1023/A:1005391716830

[8] Jia, Z., Zhang, X., Zhao, Y. and Cao, X. (2010) Enhancement of lovastatin production by supplementing polyketide antibiotics to the submerged culture of Aspergillus terreus. Applied Biochemistry and Biotechnology, 160, 2014-2025. doi:10.1007/s12010-009-8762-1

[9] Kim, H., Moon, J.Y., Kim, H., Lee, D.S., Cho, M., Choi, H.K., Kim, Y.S., Mosaddik, A. and Cho, S.K. (2010) Antioxidant and antiproliferative activities of mango (Mangifera indica L.) flesh and peel. Food Chemistry, 121, 429436. doi:10.1016/j.foodchem.2009.12.060

[10] Pandey, A. (2003) Solid-state fermentation. Biochemical Engineering Journal, 13, 81-84. doi:10.1016/S1369-703X(02)00121-3

[11] Wei, P., Xu, Z. and Cen, P. (2007) Lovastatin production by Aspergillus terreus in solid state fermentation. Journal of Zhejiang, 8, 1521-1526. doi:10.1631/jzus.2007.A1521

[12] Vilches Ferron, M.A., Casas Lopez, J.L., Sanchez Perez, J.A., Fernandez Sevilla, J.M. and Chisti, Y. (2005) Rapid screening of Aspergillus terreus mutants for overproduction of lovastatin. World Journal of Microbiology \& Biotechnology, 21, 123-125. doi:10.1007/s11274-004-3045-Z

[13] Valera, H.R., Gomes, J., Lakshmi, S., Gururaja, R., Suryanarayan, S. and Kumar, D. (2005) Lovastatin production by solid state fermentation using Aspergillus flavipes. Enzyme and Microbial Technology, 37, 521-526. doi:10.1016/j.enzmictec.2005.03.009

[14] Chen, F. and Hu, X. (2005) Study on red fermented rice with high concentration of monacolin $\mathrm{K}$ and low concentration of citrinin. International Journal of Food Microbiology, 103, 331-337. doi:10.1016/j.ijfoodmicro.2005.03.002

[15] Pansuriya, R.C. and Singhal, R.S. (2010) Response surface methodology for optimisation of production of lovastatin by solid state fermentation. Brazilian Journal of Microbiology, 41, 164-172. doi:10.1590/S1517-83822010000100024

[16] Sayyad, S.A., Panda, B.P., Javed, S. and Ali, M. (2007) Optimization of nutrient parameters for lovastatin production by Monascus purpureus MTCC 369 under submerged fermentation using response surface methodology. Applied Microbiology and Biotechnology, 73, 1054-1058. doi:10.1007/s00253-006-0577-1 